\title{
Atomic Layer Deposition of Tin Monosulfide Thin Films
}

\section{Citation}

Sinsermsuksakul, Prasert, Jae Yeong Heo, Wontae Noh, Adam S. Hock, and Roy G. Gordon. 2011. Atomic layer deposition of tin monosulfide thin films. Advanced Energy Materials 1(6): $1116-1125$.

\section{Published Version}

doi:10.1002/aenm.201100330

\section{Permanent link}

http://nrs.harvard.edu/urn-3:HUL.InstRepos:5366599

\section{Terms of Use}

This article was downloaded from Harvard University's DASH repository, and is made available under the terms and conditions applicable to Open Access Policy Articles, as set forth at http:// nrs.harvard.edu/urn-3:HUL.InstRepos:dash.current.terms-of-use\#OAP

\section{Share Your Story}

The Harvard community has made this article openly available.

Please share how this access benefits you. Submit a story.

Accessibility 


\title{
Atomic Layer Deposition of Tin Monosulfide Thin Films
}

\author{
Prasert Sinsermsuksakul, Jaeyeong Heo, Wontae Noh, Adam S. Hock, and Roy G. Gordon* \\ P. Sinsermsuksakul, Dr. J. Heo, Dr. W. Noh, Dr. A. S. Hock, and Prof. R. G. Gordon \\ Department of Chemistry and Chemical Biology, Harvard University, Cambridge, \\ Massachusetts 02138, USA. \\ *E-mail: gordon@,chemistry.harvard.edu
}

Keywords: atomic layer deposition; electro-optical materials; photovoltaic materials; thin films

\begin{abstract}
Thin film solar cells made from earth-abundant, non-toxic materials are needed to replace the current technology that uses $\mathrm{Cu}(\mathrm{In}, \mathrm{Ga})(\mathrm{S}, \mathrm{Se})_{2}$ and $\mathrm{CdTe}$, which contain scarce and toxic elements. One promising candidate absorber material is tin monosulfide $(\mathrm{SnS})$. In this report, pure, stoichiometric, single-phase $\mathrm{SnS}$ films were obtained by atomic layer deposition (ALD) using the reaction of $\operatorname{bis}\left(N, N^{\prime}\right.$-diisopropylacetamidinato)tin(II) [ $\left.\mathrm{Sn}\left(\mathrm{MeC}\left(\mathrm{N}-{ }^{i} \mathrm{Pr}\right)_{2}\right)_{2}\right]$ and hydrogen sulfide $\left(\mathrm{H}_{2} \mathrm{~S}\right)$ at low temperatures $\left(100\right.$ to $\left.200{ }^{\circ} \mathrm{C}\right)$. The direct optical band gap of $\mathrm{SnS}$ is around $1.3 \mathrm{eV}$ and strong optical absorption $\left(\alpha>10^{4} \mathrm{~cm}^{-1}\right)$ is observed throughout the visible and near-infrared spectral regions. The films are p-type semiconductors with carrier concentration on the order of $10^{16} \mathrm{~cm}^{-3}$ and hole mobility $1-4 \mathrm{~cm}^{2} \mathrm{~V}^{-1} \mathrm{~s}^{-1}$ in the plane of the films. The electrical properties are anisotropic, with three times higher mobility in the direction through the film, compared to the in-plane direction.
\end{abstract}

\section{Introduction}

To achieve cost-effective thin film solar cells for large-scale production of solar energy, the absorbing semiconductor material used in the device needs to satisfy many requirements. First, the constituent elements should be inexpensive, non-toxic, and abundant. Second, to obtain high energy conversion efficiency, the material should have appropriate optical and electrical properties such as a suitable optical band gap, a high optical absorption coefficient, a high quantum yield for the excited carriers, a long carrier diffusion length, and a 
low recombination velocity. In this aspect, tin monosulfide $(\mathrm{SnS})$ satisfies some of these criteria and thus is a promising candidate as an absorber material for solar cell. Its constituent elements (tin and sulfur) are inexpensive, environmental friendly, and abundant in nature. This feature gives it an advantage over the current best-developed thin film photovoltaic (PV) cells made from $\mathrm{Cu}(\mathrm{In}, \mathrm{Ga})(\mathrm{S}, \mathrm{Se})_{2}$ (CIGS) and $\mathrm{CdTe}$, which contain toxic $\mathrm{Cd}$ and the rare elements In, Ga, Se, and Te. Moreover, the binary compound $\mathrm{SnS}$ provides much simpler chemistry than multicomponent $\mathrm{Cu}_{2} \mathrm{ZnSnS}_{4}$ (CZTS), one of the most promising earthabundant absorber materials, with solar conversion efficiency up to $9.6 \%{ }^{[1]}$ In addition, $\mathrm{SnS}$ has proper optical properties for PV application; it has an indirect optical band gap of 1.0-1.1 $\mathrm{eV}$ and a high absorption coefficient (greater than $10^{4} \mathrm{~cm}^{-1}$ ) above the direct absorption edge at $1.3-1.5 \mathrm{eV} \cdot{ }^{[2-6]} \mathrm{SnS}$ crystallizes in an orthorhombic unit cell, with lattice parameters of $a=$ $4.334 \AA, b=11.200 \AA$, and $c=3.987 \AA,{ }^{[7]}$ which can be viewed as a distorted rocksalt $(\mathrm{NaCl})$ structure. It is composed of double SnS layers perpendicular to the $b$ axis with tin and sulfur atoms covalently bonded within the layers and weak van der Waals bonds between the layers. $^{[8]}$ The double layer held by van der Waals forces in $\mathrm{SnS}$ is expected to give a chemically inert surface with few surface states. ${ }^{[9]}$ This defect-tolerant surface might reduce the carrier recombination loss due to defects at p-n junctions and at grain boundaries.

Despite these promising properties, solar cells based on $\mathrm{SnS}$ absorbers have not achieved conversion efficiency higher than $1.3 \%,{ }^{[3]}$ while theoretically such cells should be able to reach $24 \%$ efficiency. ${ }^{[10]}$ This poor performance may be due to defects and/or impurities in SnS layers that result from the preparation methods used to make the films.

Tin monosulfide films have been deposited from various techniques, which can be roughly divided into three categories. The first method involves solution-based techniques such as chemical bath deposition (CBD),${ }^{[9,11]}$ successive ionic layer adsorption and reaction $(\mathrm{SILAR}),{ }^{[12,13]}$ and electrochemical deposition $(\mathrm{ECD}) .{ }^{[2,5,14,15]} \mathrm{A}$ second technique is physical vapor deposition from a $\mathrm{SnS}$ target such as thermal evaporation, ${ }^{[16-18]} \mathrm{RF}$ 
sputtering, ${ }^{[19]}$ and electron beam evaporation. ${ }^{[20]}$ The last method uses transport by chemical vapors such as chemical spray pyrolysis, ${ }^{[21-23]}$ chemical vapor deposition (CVD), ${ }^{[6,24-27]}$ and atomic layer deposition (ALD). ${ }^{[28]}$ Due to various oxidation states of tin $(0,+2$, and +4$)$, traces of other phases (i.e. $\mathrm{Sn}, \mathrm{Sn}_{2} \mathrm{~S}_{3}$, and $\mathrm{SnS}_{2}$ ) have often been co-deposited into the films as reported by several authors. ${ }^{[2,16,27,29]}$ To prevent the formation of $\mathrm{Sn}_{2} \mathrm{~S}_{3}$ and $\mathrm{SnS}_{2}$ phases, relatively high deposition temperatures are needed in thermal evaporation (above $275^{\circ} \mathrm{C}$ ) ${ }^{[17]}$ and CVD (above $500{ }^{\circ} \mathrm{C}$ ) ${ }^{[26,30]}$. Although pure SnS phase can be obtained at certain substrate temperatures or growth conditions, the chemical composition of the films usually deviates from ideal stoichiometric $\mathrm{SnS}$ by as much as $10-20 \%$. For vapor-based deposition techniques such as chemical spray pyrolysis and thermal evaporation, this effect is attributed to the high vapor pressure of sulfur, which evaporates out from the deposited film. ${ }^{[21,31]}$ Nonstoichiometric $\mathrm{SnS}$ caused by either $\mathrm{Sn}^{+2}$ vacancies ${ }^{[32,33]}$ or excess tin atoms ${ }^{[6,20]}$ contains deep acceptor states with an activation energy $\left(E_{a}\right)$ in the range between 0.22 and $0.45 \mathrm{eV}^{[6,20 \text {, }}$ ${ }^{32-36]}$ depending on the deposition technique. The deep acceptor states, which could act as carrier recombination catalysts, are expected to lower the solar energy conversion efficiency. In addition to other binary compounds and the non-stoichiometric problem, solution-based deposition methods such as CBD and ECB give films contaminated by oxygen in the forms of $\mathrm{SnO}_{2}$ or $\mathrm{SO}_{4}{ }^{-2} \cdot{ }^{[2,5]}$ Chlorine contamination was also reported in $\mathrm{SnS}$ films grown by CVD using tin chloride. ${ }^{[6,24]}$

ALD SnS was reported by Kim et al. using the reaction of tin 2,4-pentanedionate $\left(\mathrm{Sn}(\mathrm{acac})_{2}\right)$ and hydrogen sulfide $\left(\mathrm{H}_{2} \mathrm{~S}\right) \cdot{ }^{\left[{ }^{[28]}\right.}$ However, the growth rate was relatively low $(0.24$ $\AA$ cycle $\left.{ }^{-1}\right)$, which might be partly because Sn-O bonds $\left(532 \mathrm{~kJ} \mathrm{~mol}^{-1}\right)$ are stronger than $\mathrm{Sn}-\mathrm{S}$ bonds $\left(464 \mathrm{~kJ} \mathrm{~mol}^{-1}\right),{ }^{[37]}$ resulting in an unfavorable thermodynamic enthalpy change. Optical properties were measured only on a very thin film $(23 \mathrm{~nm})$ and crystal structure and electrical properties of the film were not studied. 
In this report, we present ALD of pure, stoichiometric, single-phase SnS films from the reaction of $\operatorname{bis}\left(N, N^{\prime}\right.$-diisopropylacetamidinato)tin(II) $\left[\mathrm{Sn}\left(\mathrm{MeC}\left(\mathrm{N}-{ }^{i} \mathrm{Pr}\right)_{2}\right)_{2}\right]$, referred to as $\mathrm{Sn}(\mathrm{amd})_{2}$ in this work, and $\mathrm{H}_{2} \mathrm{~S}$ at substrate temperatures between 100 and $200{ }^{\circ} \mathrm{C}$. The utilization of a $\mathrm{Sn}(\mathrm{II})$, rather than $\mathrm{Sn}(\mathrm{IV})$ precursor used in previously reported CVD processes, ${ }^{[6,26,29,30]}$ mitigates possible contamination by $\mathrm{Sn}_{2} \mathrm{~S}_{3}$ and $\mathrm{SnS}_{2}$ phases. Moreover, the deposition temperature is relatively low, thus overcoming the problem of sulfur-deficiency due to sulfur re-evaporation. Low temperature growth of $\mathrm{SnS}$ also enables the formation of solar cells on thermally sensitive substrates such as flexible polymers. The deposited $\mathrm{SnS}$ films were thoroughly characterized by their elemental composition, surface morphology, crystal structure, optical, and electrical properties. These SnS films possess high potential for use in photovoltaic devices.

\section{Results and Discussion}

\subsection{ALD Growth Behavior}

Figure 1(a) and 1(b) show the effect of $\mathrm{Sn}(\mathrm{amd})_{2}$ and $\mathrm{H}_{2} \mathrm{~S}$ exposures on the growth per cycle of SnS films deposited for 1000 cycles at a substrate temperature of $120{ }^{\circ} \mathrm{C}$. To saturate the surface reactions, minimum exposures of 1.5 and 1.1 Torr's of $\mathrm{Sn}(\mathrm{amd})_{2}$ and $\mathrm{H}_{2} \mathrm{~S}$ are required for each ALD cycle, respectively. The thicknesses of SnS films are uniform across the deposition zone (30 $\mathrm{cm}$ in length) within the XRF measurement error $(\sim 3 \%)$. With lower exposure to either precursor, the film thickness at the outlet is roughly $10-15 \%$ thinner than that at the inlet. Unless mentioned otherwise, exposures of 1.5 Torr's of $\mathrm{Sn}(\mathrm{amd})_{2}$ and 1.1 Torr $\cdot \mathrm{s}$ of $\mathrm{H}_{2} \mathrm{~S}$ were employed in subsequent experiments. Figure 1(c) shows the linear relationship between the film thickness and the number of cycles, which is the characteristic of ideal layer-by-layer ALD growth. From the slope, the deposition rate of $\mathrm{SnS}$ at $120{ }^{\circ} \mathrm{C}$ on a thermal oxide $\left(\mathrm{SiO}_{2}\right)$ substrate is $0.90 \pm 0.02 \AA$ cycle $^{-1}$. A small positive y-intercept within the 
measurement error indicates that ALD SnS initiates growth immediately without any incubation delay on $\mathrm{SiO}_{2}$ surfaces.

Figure 2 reveals that the growth rates of $\mathrm{SnS}$ films remain roughly constant over the deposition temperature range of $100-250{ }^{\circ} \mathrm{C}$ with slightly decreasing values toward higher temperatures. The growth rate at the inlet and the outlet of the deposition zone are the same between 100 and $200{ }^{\circ} \mathrm{C}$, indicating uniform film deposition across $30 \mathrm{~cm}$ length within this temperature range. The growth rate difference between the inlet and the outlet becomes noticeable at $250{ }^{\circ} \mathrm{C}$ and dramatically increases at $300{ }^{\circ} \mathrm{C}$. This thickness non-uniformity above $250{ }^{\circ} \mathrm{C}$ is the result of tin precursor decomposition at high temperature, indicated by carbon detection in these films by XPS, which will be discussed later. Based on this result, the ALD temperature window for $\mathrm{SnS}$ film is between 100 and $200{ }^{\circ} \mathrm{C}$. The growth rate of 0.86 $0.90 \AA$ cycle $^{-1}$ presented here is about 4 times higher than the value $\left(0.22-0.24 \AA\right.$ cycle $\left.^{-1}\right)$ obtained from a $\beta$-diketonate precursor. ${ }^{[28]}$

\subsection{Surface morphology and topography}

Figure 3 shows the surface morphologies of $\sim 90$ nm-thick $\mathrm{SnS}$ films (1000 cycles) deposited at $120,200,250$, and $300{ }^{\circ} \mathrm{C}$, as taken by SEM. At $120{ }^{\circ} \mathrm{C}$, the $\mathrm{SnS}$ film is composed of small grains with rectangular-plate shape coalescing together. From the crosssectional view, the lateral grain size of the film at $200{ }^{\circ} \mathrm{C}$ is noticeably larger than that at 120 ${ }^{\circ} \mathrm{C}$. At 250 and $300{ }^{\circ} \mathrm{C}$, sharp crystal facets can be observed on each $\mathrm{SnS}$ grain which indicates improved crystallinity of the films. In general, the grain size and crystallinity of $\mathrm{SnS}$ increases with increasing growth temperature. Nonetheless, the film surface becomes much rougher above $250{ }^{\circ} \mathrm{C}$. The effect of crystallinity and surface roughness can be observed by eye; below $200{ }^{\circ} \mathrm{C}$, the SnS films appear smooth, shiny, uniform, and pin-hole free. In contrast, the films deposited above $250{ }^{\circ} \mathrm{C}$ look rough and have several pin-holes.

Due to high surface roughness, pin-hole problems, and precursor decomposition at high growth temperatures, thicker $\mathrm{SnS}$ films were deposited for further optical and electrical 
characterization only at substrate temperatures of $200{ }^{\circ} \mathrm{C}$ or below. The SEMs of SnS films deposited for 4000 cycles at $120^{\circ} \mathrm{C}(\sim 370 \mathrm{~nm})$ and $200{ }^{\circ} \mathrm{C}(\sim 330 \mathrm{~nm})$ are shown in Figure 4. From the plan-view, the grain shapes of thicker $\mathrm{SnS}$ films are elongated platelets oriented perpendicular to the substrate surface. From the cross-sectional view, the films have columnar structure with grain boundaries perpendicular to the substrate. The grain size in the elongated direction is about the same size as the film thickness.

\subsection{Crystal structure}

Figure 5 shows the XRD patterns of $\mathrm{SnS}$ films deposited at 120 and $200{ }^{\circ} \mathrm{C}$ and at two different film thicknesses for each substrate temperature. These XRD spectra correspond to the known orthorhombic structure of $\mathrm{SnS}$ with the average lattice parameters of $a=4.30 \AA, b$ $=11.20 \AA$, and $c=3.99 \AA$, calculated from least square fitting to the Bragg peaks. The crystal lattice parameters of the SnS films match well with Herzenbergite SnS (JCPDS No. 39-0354, $a=4.3291 \AA, b=11.1923 \AA, c=3.9838 \AA$ ). Table 1(a) summarizes the main Bragg peaks of $\mathrm{SnS}$ and the average grain size calculated from Scherrer formula. ${ }^{[38]}$ The Bragg angle $\theta$ and full width at half maximum (FWHM) of each XRD peak were determined by fitting a Gaussian distribution to the experimental values. The shape factor used for the calculation is 0.9 (spherical grain shape). Since the grain shape is not exactly spherical, the calculated values only present rough estimation for comparison.

From the intensity ratios shown in Table 1(b), the change in preferred crystal orientation from the (040) plane to the (111) plane is observed as the film thickness increases. Moreover, the intensities of the (101) and (002) planes significantly increase, while that of the (040) plane noticeably decreases. This result indicates that when the films grow thicker, the $\{010\}$ layer planes switch from parallel to perpendicular to the substrate surface. This switching of crystal orientation with increasing film thickness agrees well with the observed grain size variations in the films deposited at $120{ }^{\circ} \mathrm{C}$ shown in Table 1(a); the average grain

size determined from (040) peaks is much smaller than those from other peaks since only 
during the initial growth does this crystallographic plane lie parallel to the substrate surface. The smaller grains in the initial film growth at $120{ }^{\circ} \mathrm{C}$ can be seen visually from the crosssectional SEM of Figure 4(a), as indicated in the boxes. At $200{ }^{\circ} \mathrm{C}$, the thermal energy is high enough to merge these initially nucleated grains with the grains grown later, so that all the Bragg peaks show the same FWHM.

The observed switching of crystal orientation can be explained by considering the surface energies of $\mathrm{SnS}$ crystal planes. Since $\mathrm{SnS}$ is a layered compound with the layer plane perpendicular to the $b$ crystallographic axis, the $\{010\}$ planes have much lower surface energy than $\{100\}$ and $\{001\}$ planes at the surface boundary. When SnS starts to nucleate on the substrate surface, $\{010\}$ planes would be preferred to align parallel to the substrate to minimize the surface energy. Once the film grows thicker, the surface areas (plane defects) are mainly from the grain boundaries within the film rather than from the top surface. Thus, the minimum surface energy is to have $\{010\}$ planes parallel to the grain boundaries, which is perpendicular to the substrate surface due to the nature of columnar structure in this case. In single crystals, the hole mobility along the layer direction is about 10 times higher than that in the perpendicular direction. ${ }^{[39]}$ Therefore, this preferred orientation of having layer planes perpendicular to the substrate is desirable in solar cells since the carrier transport occurs within the layer plane which has higher mobility and is also along the defect tolerant surfaces.

\subsection{Film composition and purity}

\subsubsection{Phase purity}

Mathew et al. reported traces of $\mathrm{Sn}_{2} \mathrm{~S}_{3}$ and $\mathrm{SnS}_{2}$ in the $\mathrm{SnS}$ films grown by pulsed electrodeposition that cannot be detected by XRD but can be observed by Raman spectroscopy. ${ }^{[2]}$ To confirm the phase purity, Raman spectra were taken of the ALD SnS films grown at between 120 and $300{ }^{\circ} \mathrm{C}$. Figure 6 shows the Raman peaks of ALD SnS detected at $68,94,162,191,219$, and $288 \mathrm{~cm}^{-1}$, all of which match well with those from single crystal SnS observed at 40, 49, 70, 85, 95, 164, 192, 218, and $290 \mathrm{~cm}^{-1} .^{[40]}$ This result confirms that 
the films grown at $120-300{ }^{\circ} \mathrm{C}$ are pure $\mathrm{SnS}$ without any contamination from $\mathrm{SnS}_{2}$ and $\mathrm{Sn}_{2} \mathrm{~S}_{3}$, which have their strongest Raman peaks at around 312 and $307 \mathrm{~cm}^{-1}$, respectively.

Due to the insensitivity of XRD and Raman spectroscopy to amorphous phases, transmission electron microscopy (TEM) was used to look for amorphous phase between crystallite grains. Figure 7 shows TEM micrograph and selected area electron diffraction (SAED) of a $25 \mathrm{~nm}$-thick $\mathrm{SnS}$ film deposited at $120{ }^{\circ} \mathrm{C}$. These results show that ALD SnS films do not contain significant amounts of amorphous phase despite being deposited at relatively low temperature. The utilization of a $\mathrm{Sn}(\mathrm{II})$ precursor rather than a $\mathrm{Sn}(\mathrm{IV})$

precursor $^{[6,26,29,30]}$ broadens the narrow substrate temperature window reported previously and provides only pure $\mathrm{SnS}$ over a wider range of temperature.

\subsubsection{Stoichiometry}

All the as-deposited films grown between 100 and $200{ }^{\circ} \mathrm{C}$ were measured to be stoichiometric $\mathrm{SnS}$ to within $\pm 1 \%$, which is the sensitivity limit of the RBS analysis shown in Figure 8. The atomic ratio of tin to sulfur deviates from 1.00 to 1.04 and 1.09 at the deposition temperature of 250 and $300{ }^{\circ} \mathrm{C}$, respectively. This change in atomic ratio happens in the same temperature range as the decomposition of the tin precursor, above $250{ }^{\circ} \mathrm{C}$. Reddy et al. reported a stoichiometric $\mathrm{SnS}$ obtained from thermal evaporation technique at the substrate temperature of $300{ }^{\circ} \mathrm{C} .{ }^{[4]}$ However, using the same deposition condition, stoichiometric SnS can be obtained only for films thicker than $1 \mu \mathrm{m}$; the atomic ratio of $\mathrm{Sn}$ to $\mathrm{S}$ increases almost linearly from 1.0 at $1.2 \mu \mathrm{m}$-thick to 1.1 at $100 \mathrm{~nm}$-thick. ${ }^{[31]} \mathrm{Such}$ a thickness effect on film composition has not been observed in our ALD SnS films; all ALD SnS films deposited below $200{ }^{\circ} \mathrm{C}$ in the thickness range of $50-370 \mathrm{~nm}$ are stoichiometric $\mathrm{SnS}$ with tin to sulfur atomic ratio of $1.00 \pm 0.01$. This stoichimetric $\mathrm{SnS}$ is expected to provide a low density of native point defects and $\mathrm{Sn}^{2+}$ vacancies in the material. The density of the ALD film, calculated from atomic area density (by RBS) and film thickness (by SEM), is about 4.6 
$\mathrm{g} \mathrm{cm}^{-3}$. This value is $88 \%$ of the bulk density of $\operatorname{SnS}\left(5.2 \mathrm{~g} \mathrm{~cm}^{-3}\right)$, which is relatively high for thin polycrystalline films.

\subsubsection{Elemental purity}

The incorporation of carbon is sometimes found in films deposited from a metal organic precursor due to incomplete dissociation of organic ligands from the metal center at low growth temperature or precursor decomposition at high growth temperature. Figure 9(a) shows a representative XPS spectrum of ALD SnS films deposited at 100-200 ${ }^{\circ} \mathrm{C}$. Oxygen and carbon $1 s$ peaks were observed only at the surface of the $\mathrm{SnS}$ film due to ambient contamination. After Ar sputtering for $5 \mathrm{~min}, \mathrm{O} 1 s, \mathrm{~N} 1 s$, and $\mathrm{C} 1 s$ peaks were not detected. Time-of-flight secondary ion mass spectroscopy (TOF-SIMS) analyses of films deposited at 120 and $200{ }^{\circ} \mathrm{C}$ also did not detect any oxygen, nitrogen, or carbon within the films. These results indicate that ALD $\mathrm{SnS}$ has high purity due to the clean reaction between $\operatorname{Sn}(\mathrm{amd})_{2}$ and $\mathrm{H}_{2} \mathrm{~S}$. However, for depositions above $250{ }^{\circ} \mathrm{C}, \sim 1-2 \%$ of carbon can be observed in the films. Figure 9(b) shows XPS depth profiling of $\sim 94$ nm-thick $\mathrm{SnS}$ film deposited at $250{ }^{\circ} \mathrm{C}$ detecting at the film surface, inside the $\mathrm{SnS}$ film (10 min Ar sputtering), and at the interface between the film and a $\mathrm{SiO}_{2}$ substrate (25 min Ar sputtering). Upon Ar sputtering, the $\mathrm{O} 1 \mathrm{~s}$ peak disappears inside the $\mathrm{SnS}$ film and reappears again at the film-substrate interface. In contrast, the $\mathrm{C} 1 s$ peak remains throughout the film up to the interface. The peak positions of $\mathrm{C} 1 s$ and $\mathrm{O} 1 s$ after Ar sputtering are shifted from those at the surface, which reveals that both carbon and oxygen detected after sputtering are not from the atmospheric contamination. Consequently, $\mathrm{SnS}$ film grown above $250{ }^{\circ} \mathrm{C}$ is free of oxygen and nitrogen but has $\sim 1-2 \%$ carbon incorporation into the film. This carbon contamination results from the decomposition of the tin precursor which is also indicated by the increase of the growth rate and nonstoichiometry of $\mathrm{SnS}$ film as mentioned earlier. In conclusion, ALD SnS films can be deposited at relatively low temperature in the range of $100-200{ }^{\circ} \mathrm{C}$ with precisely controlled 
thickness and the obtained films are phase-pure, stoichiometric $\mathrm{SnS}$ without any other elemental impurity.

\subsection{Optical properties}

The absorption coefficient $(\alpha)$ and the optical band gap $\left(E_{g}\right)$ of the film were determined from the transmittance $(T)$ and reflectance $(R)$ measurements. The absorption coefficient was determined based on the following formula to minimize the interference effects in the absorption of the film; ${ }^{[41]}$

$$
\alpha=\frac{1}{d} \ln \left(\frac{1}{2}\left\{\left(1-R^{\prime}\right)\left(\frac{1-R}{T}\right)+\sqrt{\left[\left(1-R^{\prime}\right)^{2}\left(\frac{1-R}{T}\right)^{2}+4 R^{\prime}\right]}\right\}\right)
$$

where $d$ is film thickness, $T$ is total transmittance, $R$ is total reflectance, and $R$ ' is a single reflectance from the film-substrate interface. Due to an unknown refractive index of SnS film in the absorbing region, $R^{\prime}$ cannot be determined. However, a good estimation of $\alpha$ can be obtained from the following approximation;

$$
\alpha \approx \frac{1}{d} \ln \left\{\left(1-R^{\prime}\right)\left(\frac{1-R}{T}\right)\right\} \approx \frac{1}{d} \ln \left\{\left(\frac{1-R}{T}\right)\right\}
$$

This approximation is valid and converges to the correct value in the high absorption region, where $(1-R) / T>>1$. Figure 10(a) shows that the absorption coefficients of $\mathrm{SnS}$ films remain over $10^{4} \mathrm{~cm}^{-1}$ in the infrared region above the band edge and over $10^{5} \mathrm{~cm}^{-1}$ in the visible region. The absorption coefficients of the $330 \mathrm{~nm}$-thick sample (diamonds) above $2.25 \mathrm{eV}$ cannot be determined accurately since the transmittance $T$ in this energy range becomes close to 0 . With $\alpha=5 \times 10^{4} \mathrm{~cm}^{-1}$, just above the band gap, the thickness of the film required to absorb $\sim 90 \%$ of the photons is only $0.5 \mu \mathrm{m}$.

The optical band gap of the film is determined from the absorption coefficient using $(\alpha \cdot h v)^{n}=A\left(h v-E_{g} \pm E_{p h}\right)$, where $A$ is a constant, $n$ is the transition probability, $E_{g}$ is the optical band gap, and $E_{p h}$ is the phonon energy. For direct transitions $\left(E_{p h}=0\right), n=2$ for allowed and $n=2 / 3$ for forbidden transitions. For indirect transitions, $n=1 / 2$ for allowed and $n=1 / 3$ for forbidden transitions. $\alpha(\lambda)$ near the band edge is best fitted to $n=2$, which 
indicates a direct allowed transition for all the samples as illustrated in Figure 10(b). The band gap of the films are determined from the plot of $(\alpha \cdot h v)^{2}$ versus photon energy by extrapolating to $\alpha \cdot h v=0$. It is worthwhile to note that without taking the interference effect into account, the determined band gap in these particular samples can be shifted as far as \pm 0.3 eV.

The band gap of $\mathrm{SnS}$ deposited at $200{ }^{\circ} \mathrm{C}$ decreases from 1.42 to $1.30 \mathrm{eV}$ when the film thickness increases from 97 to $330 \mathrm{~nm}$. Based on these results, the optical band gap of SnS films appears to decrease with increasing film thickness. The dependence of the optical band gap of $\mathrm{SnS}$ on film thickness has been previously reported by Devika and Ristov and this phenomenon has been assigned to the effect of the degree of the film crystallinity. ${ }^{[31,32,42]}$ In addition to the degree of crystallinity, the band gap shift can also stem from the change in the crystal orientation. In principle, layered structure compounds are highly anisotropic and thus can have different optical properties in different crystallographic orientations. $\mathrm{HgI}_{2}$ film has been shown to switch its preferred crystal plane parallel to the substrate from (102) to (002) when the film thickness reaches $\sim 1.45 \mu \mathrm{m}$ while its optical band gap shifts from 1.94 to $2.25 \mathrm{eV}$ for the directions perpendicular to the (102) and (002) planes, respectively. ${ }^{[43]}$

In single crystal $\mathrm{SnS}$, the lowest allowed optical energy gaps along the $a$ and $c$ crystallographic axes are 1.60 and $1.34 \mathrm{eV}$ respectively, as determined by electroreflectance and optical transmission. ${ }^{[4]}$ The smallest energy gap is, however, reported to be an indirect transition at $1.07 \mathrm{eV} .{ }^{[45]}$ Makinistian and Albanesi employed an ab initio density-functional theory with a FP-LAPW method to calculate the electronic band structure and the optical spectra of SnS. They reported that although $\mathrm{SnS}$ has an isotropic indirect energy band gap at $1.16 \mathrm{eV}$, the absorption coefficients along three principal crystallographic axes are highly anisotropic; ${ }^{[46]}$ the absorption coefficient along the $c$ axis has a sharp increase from $10^{1}$ to $10^{4}$ $\mathrm{cm}^{-1}$ at $1.21 \mathrm{eV}$. In contrast, the absorption coefficient along the $a$ and $b$ axes are quite similar 
and they have one sharp increase from $10^{1}$ to $10^{3} \mathrm{~cm}^{-1}$ at $1.20 \mathrm{eV}$ and another sudden rise from $10^{3}$ to $10^{5} \mathrm{~cm}^{-1}$ at $1.54 \mathrm{eV}$.

The smallest absorption coefficient that $T$ and $R$ measurements can detect from the films with thickness less than $500 \mathrm{~nm}$ is around $10^{2} \mathrm{~cm}^{-1}$. Below this $\alpha$ value, the absorption for a film with thickness below $500 \mathrm{~nm}$ is less than $\sim 0.005=\left(1-e^{-1 E 2 \times 500 E-7}\right)$ and therefore reliable measurement is difficult to achieve. Since the absorption coefficient close to the optical band gap $E_{g}$ at $1.1-1.2 \mathrm{eV}$ is below $10^{2} \mathrm{~cm}^{-1},{ }^{[45,46]}$ it may not be detected from our samples with $T$ and $R$ measurements. Also, interference effects must be included to analyze optical data for these nearly transparent regions of the spectrum. The optical band gaps that detected at absorption coefficients above $10^{3} \mathrm{~cm}^{-1}$ are probably from other inter-band transitions, which are not the lowest energy transition. They are different depending on sample thickness, since these transitions at higher energy gaps depend on the direction of the crystallographic orientation which changes when the film grows thicker. The change in preferred crystal orientation from $\{010\}$ to $\{111\}$ planes can be correlated to the change in the optical energy gap of the film; the detected optical band gap of SnS film changes from 1.42 to $1.30 \mathrm{eV}$ when most of the crystallite grains change (040) plane orientation from parallel to perpendicular to the substrate surface with increasing film thickness.

\subsection{Electrical properties}

Electrical properties of $\mathrm{SnS}$ films were determined by Hall measurement using the Van der Pauw method and are summarized in Table 1(d). Resistivity of the films deposited below $200{ }^{\circ} \mathrm{C}$ is roughly in the range of $50-700 \Omega \cdot \mathrm{cm}$ and correlates strongly with the grain size, crystallinity, and morphology of the films. Compared to the samples of the same average film thickness $(\sim 90-100 \mathrm{~nm}), \mathrm{SnS}$ films show lower resistivity as the growth temperature increases. Interestingly, the resistivity of the films deposited at $200{ }^{\circ} \mathrm{C}$ does not change as the film thickness increases from 97 (sample (B)) to $330 \mathrm{~nm}$ (sample (D)). Normally, the resistivity decreases as the film gets thicker, due to less carrier scattering at the grain 
boundaries as the grain size increases. However, $\mathrm{SnS}$ is a highly anisotropic material. As mentioned earlier, the hole mobility along the layer direction is about 10 times higher than that in the perpendicular direction in single crystals. ${ }^{[39]}$ Thus, in addition to grain boundary scattering, the crystal orientation is also an important factor that contributes to the electrical properties of the films. From XRD, most of the (040) plane crystallite grains change orientation from parallel to perpendicular to the substrate surface with increasing film thickness. As a result of this crystal orientation change, the resistivity of the films deposited at $200{ }^{\circ} \mathrm{C}$ does not change significantly as the film thickness increases from 97 to $330 \mathrm{~nm}$. In the case of the film deposited at $120^{\circ} \mathrm{C}$, the grain boundary scattering is expected to dominate the crystal orientation effect since the nucleation layer which favors $(040)$ preferred orientation is also observed in the thicker film.

Hall measurement revealed that $\mathrm{SnS}$ films have p-type conductivity with hole concentrations between $1 \times 10^{16}$ and $3 \times 10^{16} \mathrm{~cm}^{-3}$ and hole mobilities in the range of $1-4 \mathrm{~cm}^{2} \mathrm{~V}^{-}$ ${ }^{1} \mathrm{~s}^{-1}$. These low carrier concentrations may arise from slight deviations from stoichiometry leading to native point defects such as $\mathrm{Sn}^{+2}$ vacancies. A low carrier concentration facilitates charge separation at the $\mathrm{p}-\mathrm{n}$ junction in solar cells since the depletion width, covered by builtin electric field, extends through most of the absorber layer.

Interestingly, in a $\mathrm{Au} / \mathrm{SnS} / \mathrm{Au}$ structure, the resistivity of a $370 \mathrm{~nm}$-thick $\mathrm{SnS}$ film deposited at $120^{\circ} \mathrm{C}$ (sample (C) in Table 1) measured in vertical direction through the film was $60 \Omega \cdot \mathrm{cm}$, which is roughly three times lower than that in lateral direction $(176 \Omega \cdot \mathrm{cm})$. This anisotropic resistivity of ALD SnS mainly arises from the combination of columnar structure (grain boundaries) and preferred crystal orientation discussed earlier. At $200{ }^{\circ} \mathrm{C}$, the Au substrate has a significant effect on the growth of $\mathrm{SnS}$, yielding grain sizes enlarged as much as 10 times compared to films grown on $\mathrm{SiO}_{2}$ substrates. Therefore, $\mathrm{SnS}$ films deposited at $200{ }^{\circ} \mathrm{C}$ on $\mathrm{Au}$ substrates cannot be used for a similar estimate of the anisotropy of the mobility in different directions in the film. 


\section{Conclusions}

Tin monosulfide thin films were deposited by ALD using the reaction of $\operatorname{bis}\left(N, N^{\prime}-\right.$ diisopropylacetamidinato)tin(II) and hydrogen sulfide at substrate temperatures between 100 and $200{ }^{\circ} \mathrm{C}$. Minimum exposures of 1.5 Torr's of tin precursor and 1.1 Torr's of $\mathrm{H}_{2} \mathrm{~S}$ were required to saturate the surface reactions and obtain growth at $0.86-0.90 \AA /$ cycle. The films are polycrystalline and crystallized in a pure single orthorhombic phase of SnS with $a=4.30$ $\AA, b=11.20 \AA$, and $c=3.99 \AA$. Neither $\mathrm{SnS}_{2}$ nor $\mathrm{Sn}_{2} \mathrm{~S}_{3}$ was detected by Raman spectroscopy or XRD. TEM analysis showed that the film contains negligible amorphous phase despite the relatively low temperature deposition. All the films below $200{ }^{\circ} \mathrm{C}$ were measured to be stoichiometric SnS to within $\pm 1 \%$. No C, N, or O impurities were detected by XPS or TOFSIMS. The films have a dense, polycrystalline columnar structure. The optical band gap of the films decreased from 1.42 to $1.30 \mathrm{eV}$ when the preferred crystal orientation changed from (040) to (111) as the thickness of the films increased from 100 to $330 \mathrm{~nm}$. Their optical absorption coefficients are over $10^{4} \mathrm{~cm}^{-1}$ in the infrared above the band edge, and over $10^{5}$ $\mathrm{cm}^{-1}$ in the visible region. The lateral resistivity of the films is between 50 and $700 \Omega \cdot \mathrm{cm}$ depending on film thickness and growth temperature. Hall measurements showed that the $\mathrm{SnS}$ films have p-type conductivity with hole concentrations between $1 \times 10^{16}$ and $3 \times 10^{16} \mathrm{~cm}^{-3}$ and hole mobility in the range of $1-4 \mathrm{~cm}^{2} \mathrm{~V}^{-1} \mathrm{~s}^{-1}$ in the plane of the films. In the direction through the film, the mobility and conductivity are roughly three times higher, because of the preferred orientation of the (040) layer planes perpendicular to the surface of thicker films and the columar structure of the films. These suitable optical and electrical properties of ALD SnS films, coupled with inexpensive, non-toxic, and earth-abundant constituent elements, make this material a promising candidate for an absorber layer in thin film solar cells.

\section{Experimental procedure}


The tin precursor, bis( $N, N^{\prime}$-diisopropylacetamidinato)tin(II) was prepared according to the synthetic route depicted in Figure 11, which was adopted from the work by Lim et al. ${ }^{[47]}$ A solution of methyllithium (1.6 $\mathrm{M}$ in $\left.\mathrm{Et}_{2} \mathrm{O}, 20 \mathrm{~mL}, 0.032 \mathrm{~mol}\right)$ was added dropwise to a solution of 1,3-diisopropylcarbodiimide $(4.0 \mathrm{~g}, 0.032 \mathrm{~mol})$ in $\mathrm{Et}_{2} \mathrm{O}(75 \mathrm{~mL})$ at $-78{ }^{\circ} \mathrm{C}$. The solution was allowed to warm up to room temperature and stirred for additional two hours. This colorless solution was then slowly added to a solution of tin(II) chloride (Reagent grade $98 \%, 3.0 \mathrm{~g}, 0.016 \mathrm{~mol})$ in $\mathrm{Et}_{2} \mathrm{O}(50 \mathrm{~mL})$. This reaction mixture was stirred for 15 hours. Then, the solvent was removed under vacuum. The resulting white solid was extracted with pentane (150 mL) and filtered through Celite on a glass frit to remove $\mathrm{LiCl}$ salt. The resulting colorless filtrate was placed under vacuum to remove pentane, giving a white powder. Subsequent sublimation at $90{ }^{\circ} \mathrm{C}$ and 30 mTorr for three hours yielded pure white crystals $(5.2$ g, $81 \%)$.

SnS thin films were deposited in a custom-built hot-wall ALD reactor ${ }^{[48]}$ from the reaction of $\mathrm{Sn}(\mathrm{amd})_{2}$ and $\mathrm{H}_{2} \mathrm{~S}$. The tin precursor was kept at a constant temperature of $95{ }^{\circ} \mathrm{C}$ which gives vapor pressure of 0.64 Torr, as measured by a capacitance manometer. A gas mixture of $4 \% \mathrm{H}_{2} \mathrm{~S}$ in $\mathrm{N}_{2}$ was used as the source of sulfur. Purified $\mathrm{N}_{2}$ gas was used for assisting the delivery of $\mathrm{Sn}(\mathrm{amd})_{2}$ vapor from the precursor container to the deposition zone and also for purging between each precursor pulse. The $\mathrm{Sn}$ precursor and $\mathrm{H}_{2} \mathrm{~S}$ injection was done by using stop-flow ALD mode. Detailed explanation of the stop-flow ALD mode and the valve operation procedure can be found elsewhere. ${ }^{[49,50]}$ The exposures from each single dose of $\mathrm{Sn}(\mathrm{amd})_{2}$ and $\mathrm{H}_{2} \mathrm{~S}$ were estimated to be 0.50 and 0.36 Torr's, respectively. By changing the number of tin precursor and $\mathrm{H}_{2} \mathrm{~S}$ doses, reproducible variations in the total precursor exposure were achieved. The $\mathrm{N}_{2}$ purge time between each precursor pulse was set to be $10 \mathrm{~s}$, which is sufficient to remove the excess precursor and reaction by-products. The cycles of sequential alternation between $\mathrm{Sn}(\mathrm{amd})_{2}$ and $\mathrm{H}_{2} \mathrm{~S}$ were repeated until the desired film thickness was reached. 
Surface morphology and topology of the films were examined by using field-emission scanning electron microscopy (FESEM, Zeiss, Ultra-55). The film thickness was determined using a combination of cross-sectional SEM and X-ray fluorescence spectroscopy (XRF, Spectro, Xepos-III); the average thickness of rough films was determined by XRF utilizing a calibration curve of $\mathrm{Sn} \mathrm{L}_{\alpha 1}$ line intensity (count $\min ^{-1}$ ) versus the film thickness of smooth films measured by cross-sectional SEM. The crystal structure of the SnS films was characterized by X-ray diffraction (XRD, PANalytical X'Pert Pro) with $\mathrm{Cu} \mathrm{K}_{\alpha}$ radiation $(\lambda=$ $1.542 \AA$ ) using $\theta-2 \theta$ scan. Raman spectroscopy (Renishaw, inVia Raman microscope) with an exciting wavelength of $633 \mathrm{~nm}$ and transmission electron microscopy (TEM, JEOL 2100) were employed to check for the presence of any additional phases of tin sulfide. The elemental composition and the purity of the films were determined by Rutherford backscattering spectroscopy (RBS, Charles Evans RBS and Ionex 1.7 MV Tandetron), X-ray photoelectron spectroscopy (XPS, Surface Science, SSX-100), and Time-of-flight secondary ion mass spectroscopy (TOF-SIMS). The optical transmittance $(T)$ and reflectance $(R)$ were recorded at normal incidence using a UV-Vis-near IR spectrophotometer with an integrating sphere (Hitachi U-4100) in the wavelength range of 400 to $2500 \mathrm{~nm}$. The absorption coefficient $(\alpha)$ and the optical band gap $\left(E_{g}\right)$ were calculated from the measured optical transmittance and reflectance. The lateral resistivity, carrier concentration, and carrier mobility of the films were determined from Hall measurement according to the Van der Pauw method at room temperature. Indium pads were deposited by soldering to provide an ohmic contact to the SnS films. ${ }^{[51,52]}$ The current was supplied from a Keithley 6220 Current Source and the voltage was measured by Keithley 6514 Electrometer with input impedance $>200 \mathrm{~T} \Omega$. Due to fluctuations of the current source, the errors of carrier concentration and mobility, determined from standard deviation of the Hall voltage, are roughly $20 \%$ or less. The vertical resistivity of $\mathrm{SnS}$ film was determined by $\mathrm{I}-\mathrm{V}$ measurement from the slope of a plot of resistance through $\mathrm{Au} / \mathrm{SnS} / \mathrm{Au}$ stacks versus 1/area. The top Au electrodes were squares with 
sides $100,200,300$, or $500 \mu \mathrm{m}$ long, evaporated through a shadow mask. SnS films outside the area of the top Au electrode were removed by reactive ion etching (RIE, Nexx Systems, Cirrus 150) using $\mathrm{Cl}_{2}$ plasma.

\section{Acknowledgements}

This work was supported in part by the Dreyfus Foundation, Saint Gobain, and the National Science Foundation (NSF) under award no. CBET-1032955. This work was performed in part at the Center for Nanoscale Systems (CNS) at Harvard University, a member of the National Nanotechnology Infrastructure Network (NNIN), which is supported by NSF award no. ECS-0335765. The authors appreciate TOF-SIMS analyses taken by Saint

Gobain. The authors thank Dr. Hoon Kim for helpful discussions, Dr. Harish Bhandari for assistance in building ALD reactor, and Dr. Mark Winkler and Meng-Ju Sher for help with Hall measurements. P. Sinsermsuksakul thanks the Development and Promotion of Science and Technology Talents Project (DPST), Thailand for scholarhip funding.

\section{References}

[1] T. K. Todorov, K. B. Reuter, D. B. Mitzi, Adv. Mater. 2010, 22, E156.

[2] N. R. Mathews, H. B. M. Anaya, M. A. Cortes-Jacome, C. Angeles-Chavez, J. A. Toledo-Antonio, J. Electrochem. Soc. $2010,157, \mathrm{H} 337$.

[3] K. T. R. Reddy, N. K. Reddy, R. W. Miles, Sol. Energ. Mat. Sol. C 2006, 90, 3041.

[4] N. K. Reddy, Y. B. Hahn, M. Devika, H. R. Sumana, K. R. Gunasekhar, J. Appl. Phys. 2007, 101, 093522.

[5] M. Ichimura, K. Takeuchi, Y. Ono, E. Arai, Thin Solid Films 2000, 361, 98.

[6] A. Ortiz, J. C. Alonso, M. Garcia, J. Toriz, Semicond. Sci. Tech. 1996, 11, 243.

[7] H. Wiedemeier, H. G. V. Schnering, Z. Kristallogr. 1978, 148, 295.

[8] W. Albers, H. J. Vink, C. Haas, J. D. Wasscher, J. Appl. Phys. 1961, 32, 2220.

[9] D. Avellaneda, M. T. S. Nair, P. K. Nair, J. Electrochem. Soc. 2008, 155, D517.

[10] J. J. Loferski, J. Appl. Phys. 1956, 27, 777.

[11] E. Turan, M. Kul, A. S. Aybek, M. Zor, J. Phys. D Appl. Phys. 2009, 42, 245408.

[12] C. Gao, H. L. Shen, L. Sun, H. B. Huang, L. F. Lu, H. Cai, Mater. Lett. 2010, 64, 2177.

[13] B. Ghosh, M. Das, P. Banerjee, S. Das, Semicond. Sci. Tech. 2008, 23, 125013.

[14] F. Kang, M. Ichimura, Thin Solid Films 2010, 519, 725.

[15] J. R. S. Brownson, C. Georges, C. Levy-Clement, Chem. Mater. 2007, 19, 3080.

[16] R. W. Miles, O. E. Ogah, G. Zoppi, I. Forbes, Thin Solid Films 2009, 517, 4702.

[17] M. Devika, K. T. R. Reddy, N. K. Reddy, K. Ramesh, R. Ganesan, E. S. R. Gopal, K. R. Gunasekhar, J. Appl. Phys. 2006, 100, 023518. 
[18] J. B. Johnson, H. Jones, B. S. Latham, J. D. Parker, R. D. Engelken, C. Barber, Semicond. Sci. Tech. 1999, 14, 501.

[19] K. Hartman, J. L. Johnson, M. I. Bertoni, D. Recht, M. J. Aziz, M. A. Scarpulla, T. Buonassisi, Thin Solid Films, In Press, Corrected Proof.

[20] A. Tanusevski, D. Poelman, Sol. Energ. Mat. Sol. C. 2003, 80, 297.

[21] T. H. Sajeesh, A. R. Warrier, C. S. Kartha, K. P. Vijayakumar, Thin Solid Films 2010, 518,4370 .

[22] M. Calixto-Rodriguez, H. Martinez, A. Sanchez-Juarez, J. Campos-Alvarez, A. Tiburcio-Silver, M. E. Calixto, Thin Solid Films 2009, 517, 2497.

[23] N. K. Reddy, K. T. R. Reddy, Mater. Chem. Phys. 2007, 102, 13.

[24] B. P. Bade, S. S. Garje, Y. S. Niwate, M. Afzaal, P. O'Brien, Chem. Vapor. Depos. 2008, 14, 292.

[25] G. Barone, T. Chaplin, T. G. Hibbert, A. T. Kana, M. F. Mahon, K. C. Molloy, I. D. Worsley, I. P. Parkin, L. S. Price, J. Chem. Soc. Dalton. 2002, 1085.

[26] T. G. Hibbert, M. F. Mahon, K. C. Molloy, L. S. Price, I. P. Parkin, J. Mater. Chem. 2001, 11, 469 .

[27] L. S. Price, I. P. Parkin, A. M. E. Hardy, R. J. H. Clark, T. G. Hibbert, K. C. Molloy, Chem. Mater. 1999, 11, 1792.

[28] J. Y. Kim, S. M. George, J. Phys. Chem. C 2010, 114, 17597.

[29] G. Barone, T. G. Hibbert, M. F. Mahon, K. C. Molloy, L. S. Price, I. P. Parkin, A. M. E. Hardy, M. N. Field, J. Mater. Chem. 2001, 11, 464.

[30] I. P. Parkin, L. S. Price, T. G. Hibbert, K. C. Molloy, J. Mater. Chem. 2001, 11, 1486.

[31] M. Devika, N. K. Reddy, K. Ramesh, R. Ganesan, K. R. Gunasekhar, E. S. R. Gopal, K. T. R. Reddy, J. Electrochem. Soc. 2007, 154, H67.

[32] M. Ristov, G. Sinadinovski, I. Grozdanov, M. Mitreski, Thin Solid Films 1989, 173, 53.

[33] Y. Wang, H. Gong, B. H. Fan, G. X. Hu, J. Phys. Chem. C 2010, 114, 3256.

[34] N. K. Reddy, K. T. R. Reddy, Thin Solid Films 1998, 325, 4.

[35] M. T. S. Nair, P. K. Nair, P. K. Nair, Semicond. Sci. Tech. 1991, 6, 132.

[36] T. H. Sajeesh, N. Poornima, C. S. Kartha, K. P. Vijayakumar, Phys. Status Solidi A 2010, 207, 1934.

[37] D. R. Lide, Ed. CRC Handbook of Chemistry and Physics; 81st edition, CRC Press, 2000.

[38] A. L. Patterson, Phys. Rev. 1939, 56, 978.

[39] M. M. Nassary, J. Alloy Compd. 2005, 398, 21.

[40] H. R. Chandrasekhar, R. G. Humphreys, U. Zwick, M. Cardona, Phys. Rev. B 1977, 15, 2177.

[41] D. Ritter, K. Weiser, Opt. Commun. 1986, 57, 336.

[42] M. Devika, N. K. Reddy, F. Patolsky, K. Ramesh, K. R. Gunasekhar, Appl. Phys. Lett. 2009, 95, 261907.

[43] P. Tyagi, A. G. Vedeshwar, Phys. Rev. B 2001, 6324, 245315.

[44] G. Valiukonis, D. A. Guseinova, G. Krivaite, A. Sileika, Phys. Status Solidi. B 1986, $135,299$.

[45] W. Albers, C. Haas, F. Vandermaesen, J. Phys. Chem. Solids 1960, 15, 306.

[46] L. Makinistian, E. A. Albanesi, Phys. Status Solidi B 2009, 246, 183.

[47] B. S. Lim, A. Rahtu, J. S. Park, R. G. Gordon, Inorg. Chem. 2003, 42, 7951.

[48] D. M. Hausmann, P. de Rouffignac, A. Smith, R. Gordon, D. Monsma, Thin Solid Films 2003, 443, 1.

[49] S. K. Karuturi, L. J. Liu, L. T. Su, Y. Zhao, H. J. Fan, X. C. Ge, S. L. He, A. T. I. Yoong, J. Phys. Chem. C 2010, 114, 14843.

[50] J. Heo, A. S. Hock, R. G. Gordon, Chem. Mater. 2010, 22, 4964. 
[51] M. Devika, N. K. Reddy, F. Patolsky, K. R. Gunasekhar, J. Appl. Phys. 2008, 104, 124503.

[52] B. Ghosh, M. Das, P. Banerjee, S. Das, Solid State Sci. 2009, 11, 461. 

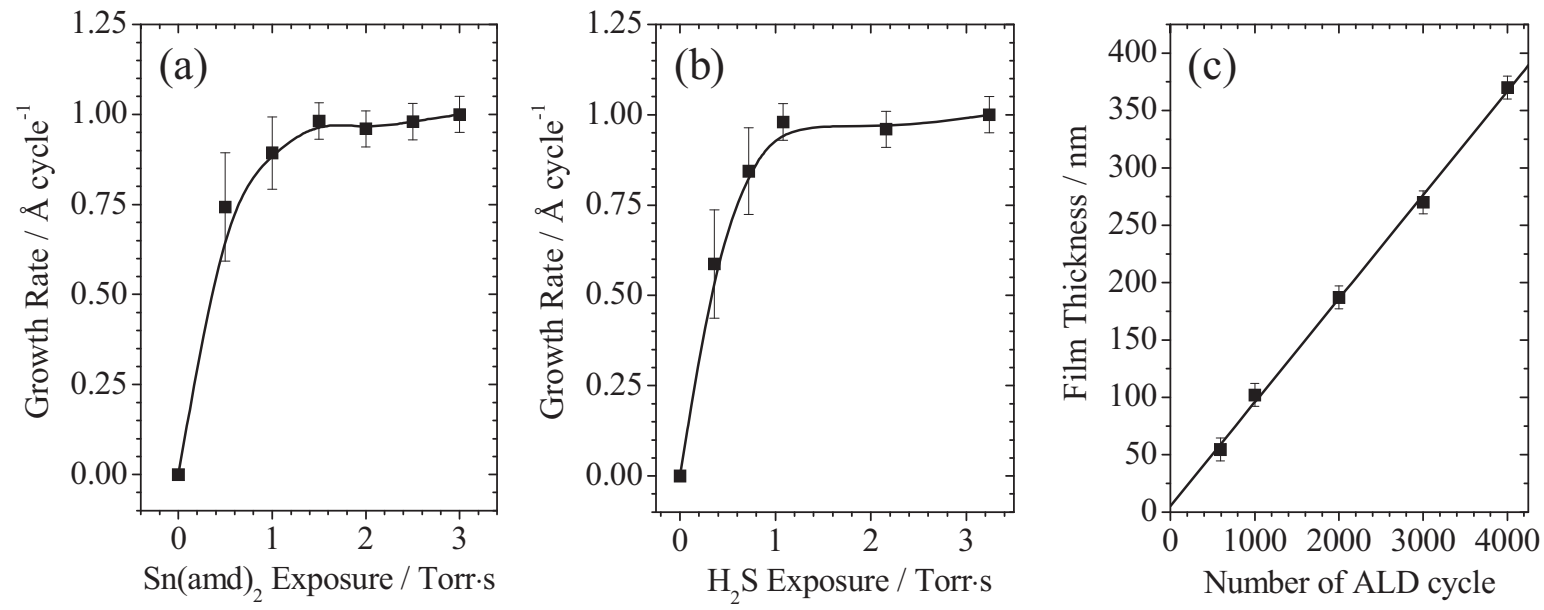

Figure 1. The growth rate of $\mathrm{SnS}$ films at a deposition temperature of $120^{\circ} \mathrm{C}$ for different exposures of (a) Sn precursor at fixed $\mathrm{H}_{2} \mathrm{~S}$ exposure of 2.2 Torr's and of (b) $\mathrm{H}_{2} \mathrm{~S}$ at fixed $\mathrm{Sn}$ precursor exposure of 1.5 Torr's. (c) The thickness of $\mathrm{SnS}$ films on $\mathrm{SiO}_{2}$ substrates using 1.5 Torr's of Sn precursor and 1.1 Torr' $\mathrm{s}$ of $\mathrm{H}_{2} \mathrm{~S}$ exposure as a function of the number of ALD growth cycles at $120{ }^{\circ} \mathrm{C}$. 


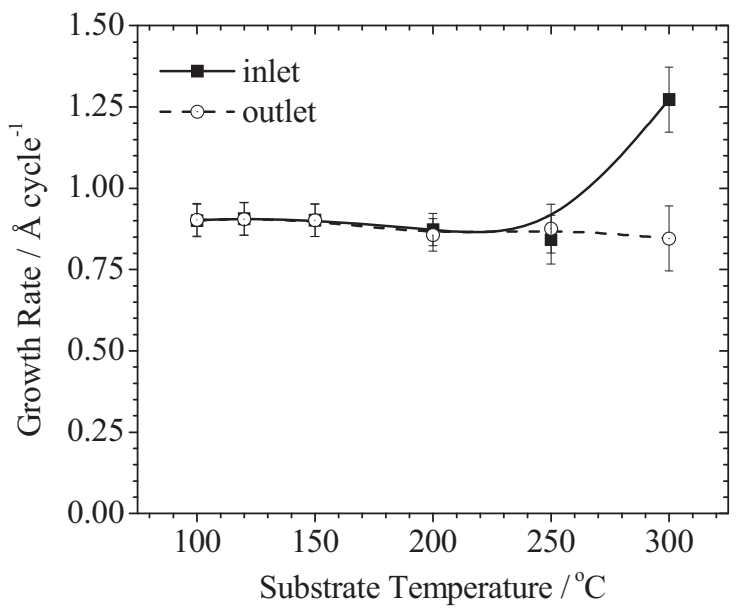

Figure 2. The growth rates of $\mathrm{SnS}$ films deposited between 100 and $300{ }^{\circ} \mathrm{C}$ at the inlet and outlet of the deposition zone $(30 \mathrm{~cm}$ in length). 

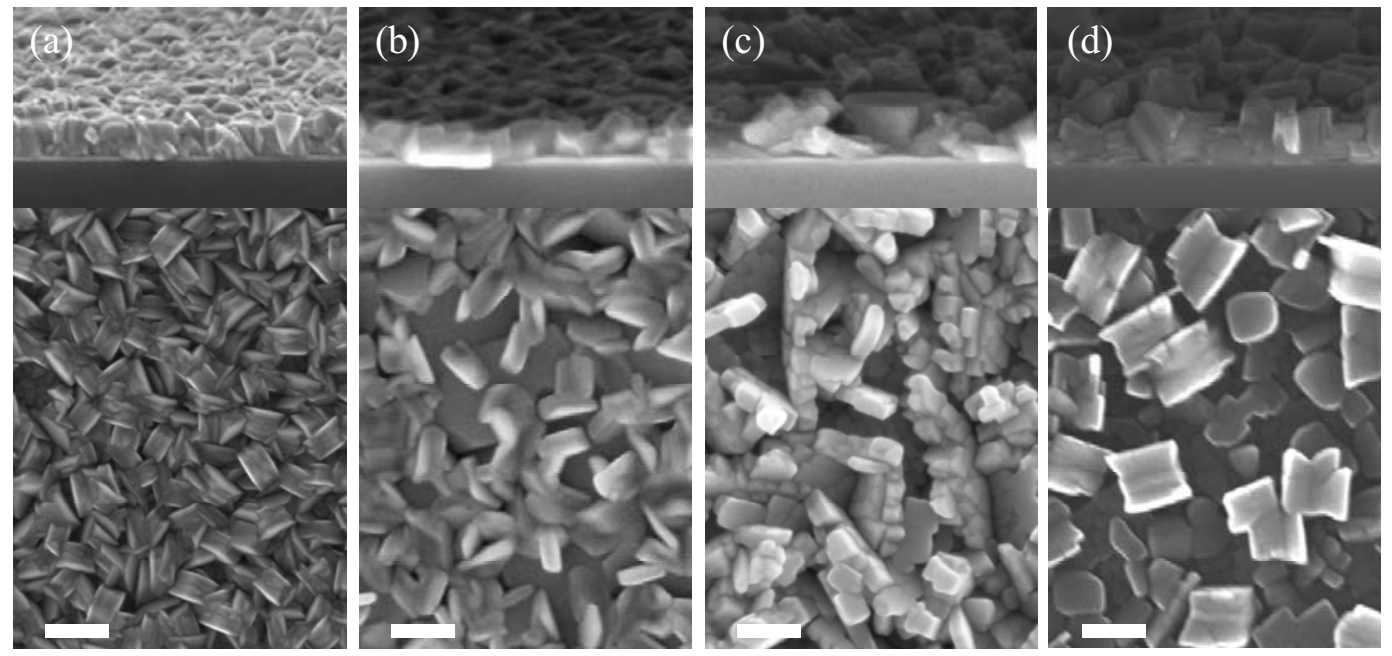

Figure 3. Plan-view and cross-sectional ( $12^{\circ}$ tilt) SEM images of $\mathrm{SnS}$ films deposited on thermal oxide $\left(\mathrm{SiO}_{2}\right)$ for $1000 \mathrm{ALD}$ cycles at (a) $120{ }^{\circ} \mathrm{C}$, (b) $200{ }^{\circ} \mathrm{C}$, (c) $250{ }^{\circ} \mathrm{C}$, and (d) 300 ${ }^{\circ} \mathrm{C}$. The scale bar is $200 \mathrm{~nm}$. 

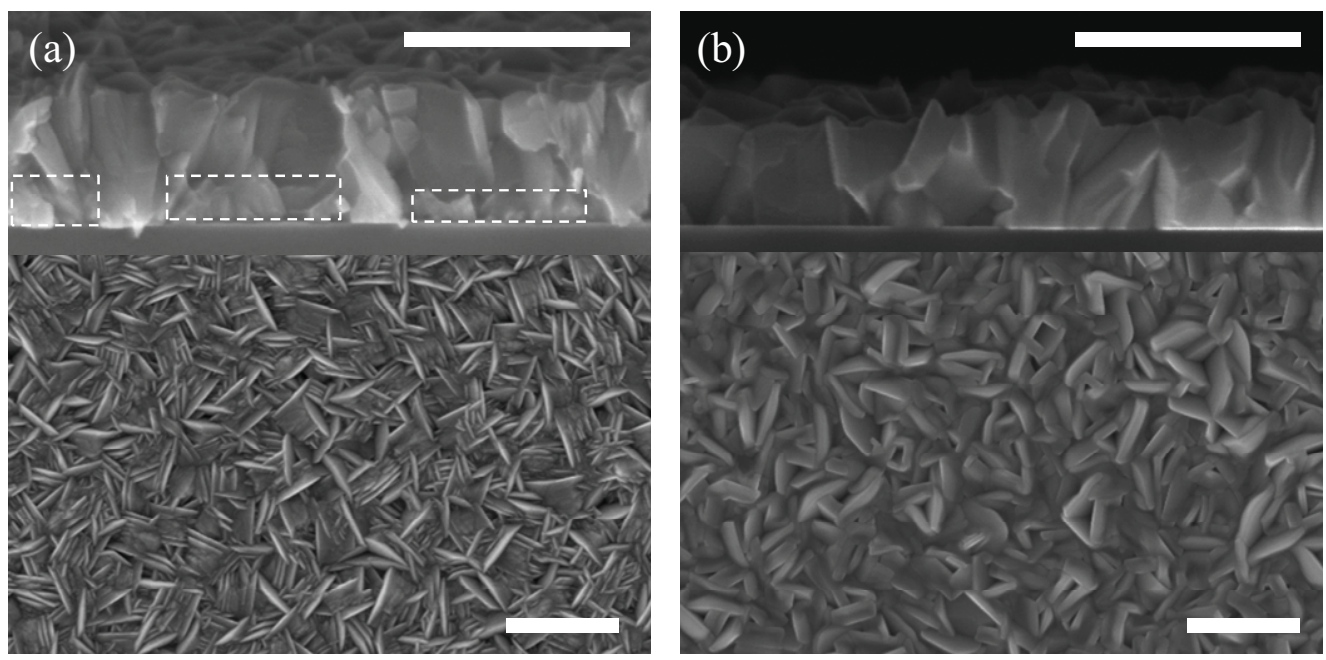

Figure 4. Plan-view and cross-sectional (12 ${ }^{\circ}$ tilt) SEM images of $\mathrm{SnS}$ films deposited on thermal oxide $\left(\mathrm{SiO}_{2}\right)$ for $4000 \mathrm{ALD}$ cycles at (a) $120{ }^{\circ} \mathrm{C}$ and (b) $200{ }^{\circ} \mathrm{C}$. The boxes in the cross-sectional SEM of (a) indicate the smaller grains formed during the initial film growth. The scale bar is $500 \mathrm{~nm}$. 

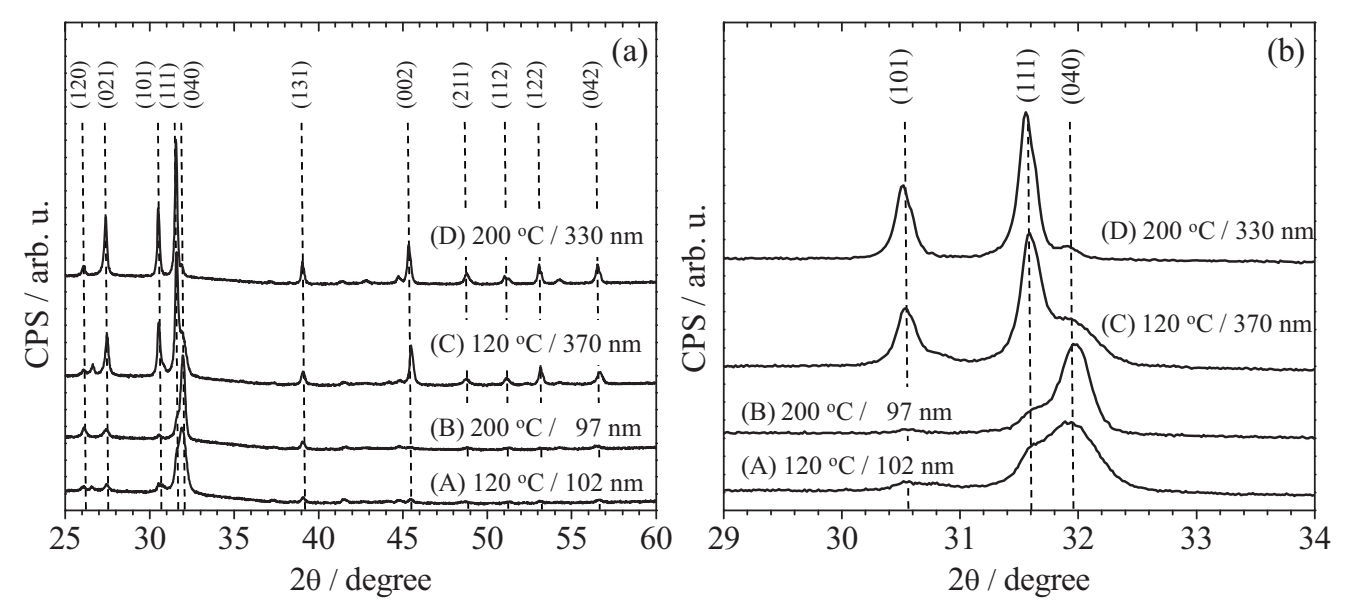

Figure 5. XRD spectra of SnS films deposited at $120{ }^{\circ} \mathrm{C}$ and $200{ }^{\circ} \mathrm{C}$ and at two different film thicknesses for each substrate temperature. (b) is the expansion of (a) to clearly show (111) and (040) peaks. 


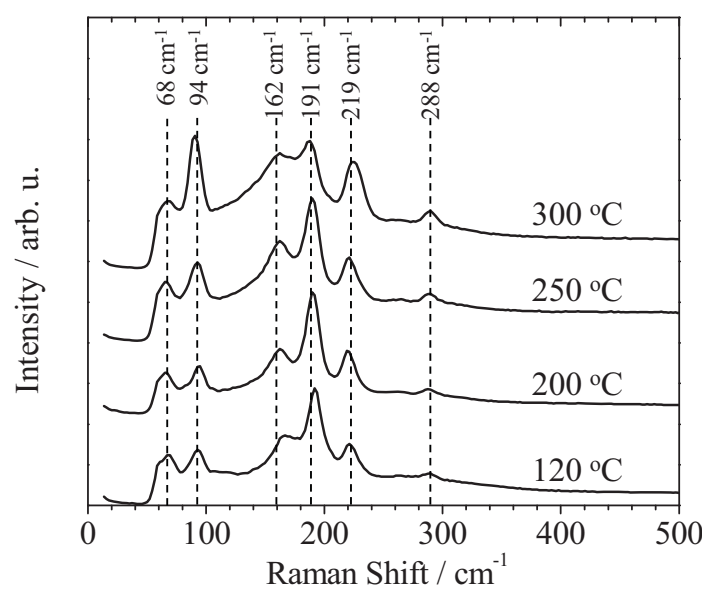

Figure 6. Raman spectra of ALD SnS films deposited between 120 and $300{ }^{\circ} \mathrm{C}$, indicating pure Herzenbergite SnS phase. 


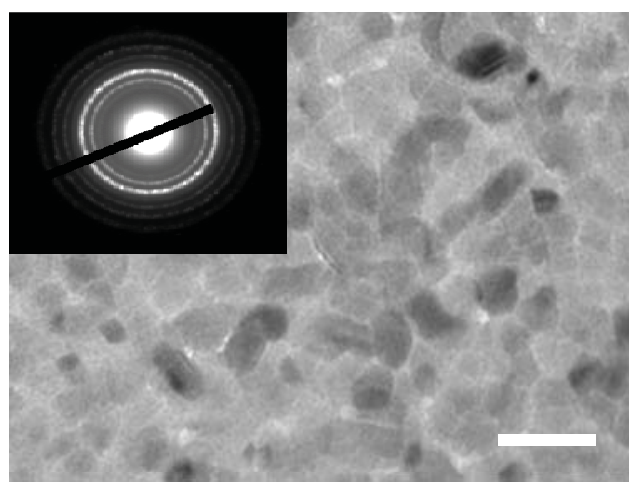

Figure 7. Plan-view TEM micrograph of a $25 \mathrm{~nm}$-thick $\mathrm{SnS}$ film deposited at $120^{\circ} \mathrm{C}$. The inset is a SAED pattern indicating a polyscrstalline structure of the film. The scale bar is 50 nm. 


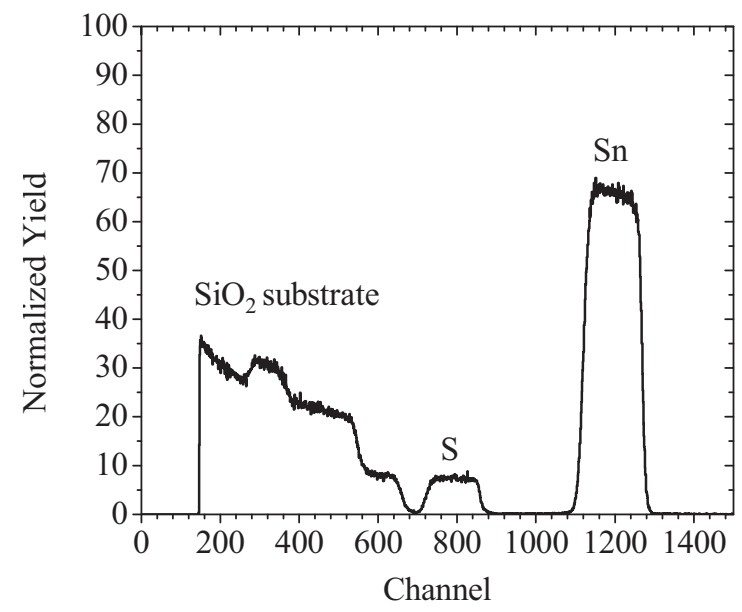

Figure 8. A typical RBS spectrum of ALD films deposited at between 100 and $200{ }^{\circ} \mathrm{C}$, indicating stoichiometric $\mathrm{SnS}$ to within $\pm 1 \%$. 

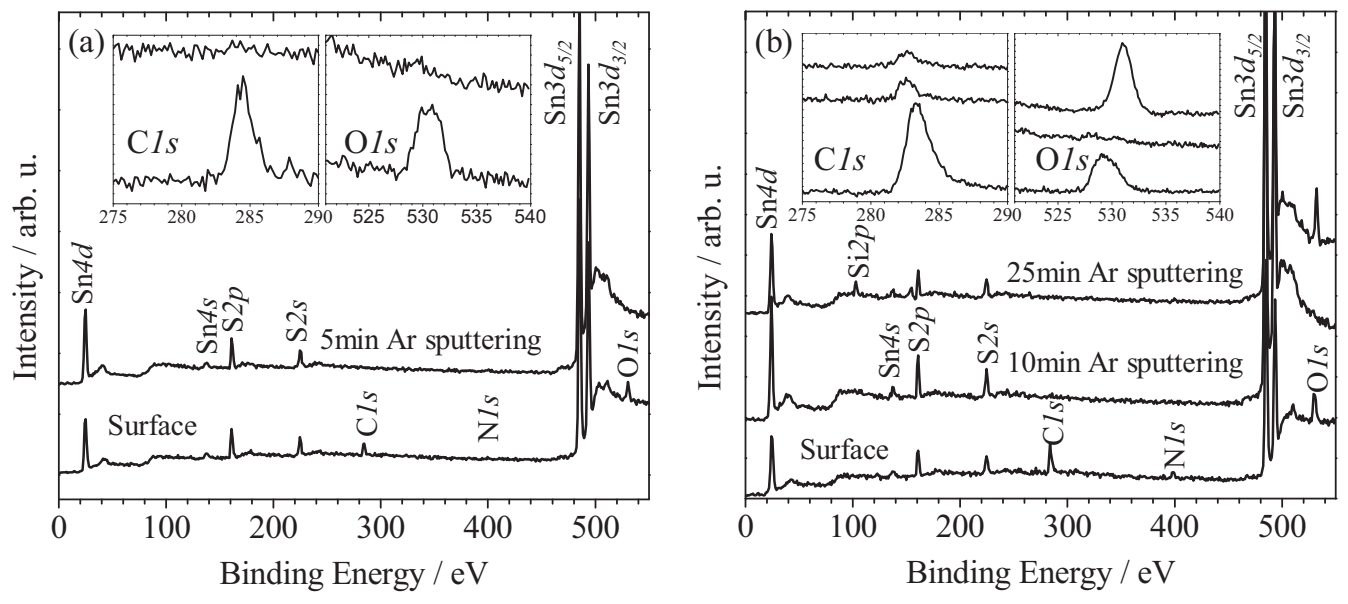

Figure 9. XPS depth-profiling of a typical ALD SnS film deposited between (a) $100-200{ }^{\circ} \mathrm{C}$ and (b) $250-300{ }^{\circ} \mathrm{C}$. 

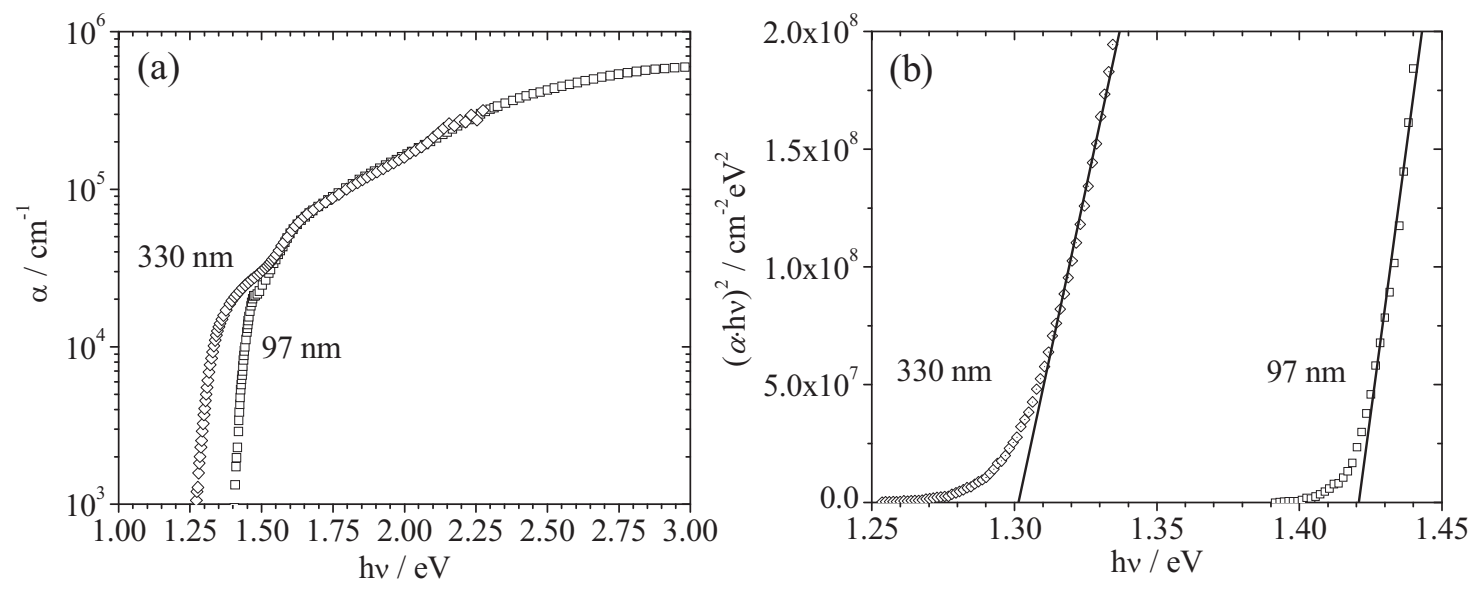

Figure 10. Optical properties of $\mathrm{SnS}$ films deposited at $200{ }^{\circ} \mathrm{C}$ at two different thicknesses. (a) absorption coefficient $\alpha$ and (b) a plot of $(\alpha \cdot h v)^{2}$ as a function of photon energy, indicating direct transition with the optical band gap $E_{g}$ at x-interception. 


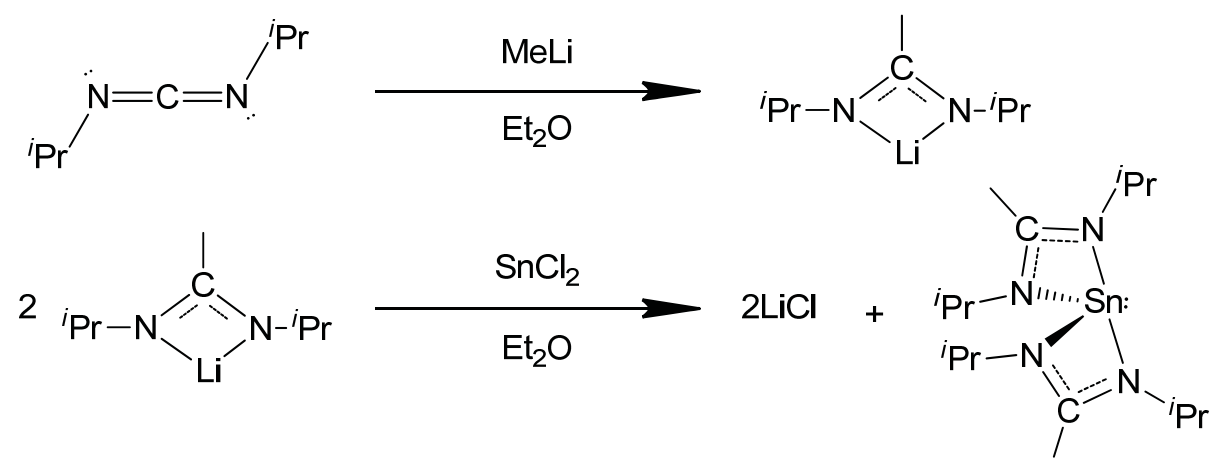

Figure 11. Synthetic route of bis( $N, N^{\prime}$-diisopropylacetamidinato)tin(II). 


\begin{tabular}{|c|c|c|c|c|c|c|}
\hline & Sample & (A) & (B) & (C) & (D) & 039-0354 \\
\hline & $\mathrm{T}_{\text {sub }}\left[{ }^{\circ} \mathrm{C}\right]$ & 120 & 200 & 120 & 200 & - \\
\hline & Film Thickness [nm] & 102 & 97 & 370 & 330 & - \\
\hline \multirow{8}{*}{ (a) } & $h k l$ & \multicolumn{5}{|c|}{$2 \theta, \tau(\mathrm{nm})$} \\
\hline & 120 & $26.08,31$ & $26.11,29$ & - & $26.09,46$ & 26.0094 \\
\hline & 021 & $27.46,29$ & $27.42,29$ & $27.27,40$ & $27.40,46$ & 27.4719 \\
\hline & 101 & - & - & $30.53,41$ & $30.53,49$ & 30.4731 \\
\hline & 111 & $31.57,32$ & $31.65,28$ & $31.59,41$ & $31.58,50$ & 31.5313 \\
\hline & 040 & $31.94,17$ & $31.98,29$ & $31.90,17$ & $31.90,50$ & 31.9711 \\
\hline & 131 & $39.07,32$ & $39.08,30$ & $39.08,37$ & $39.06,47$ & 39.3292 \\
\hline & 002 & - & - & $45.52,40$ & $45.46,43$ & 45.4946 \\
\hline \multirow{3}{*}{ (b) } & $I(111) / I(040)$ & 0.38 & 0.28 & 2.83 & 12.5 & 2.00 \\
\hline & $I(101) / I(040)$ & 0.15 & 0.06 & 1.19 & 6.25 & 1.40 \\
\hline & $I(002) / I(040)$ & $\sim 0$ & $\sim 0$ & 0.97 & 3.44 & 1.00 \\
\hline (c) & $E_{g}[\mathrm{eV}]$ & 1.42 & 1.42 & 1.30 & 1.30 & - \\
\hline \multirow{3}{*}{ (d) } & $\rho[\Omega \cdot \mathrm{cm}]$ & 692 & 62 & 172 & 59 & - \\
\hline & Hole density $\left[\mathrm{cm}^{-3}\right]$ & $1.1 \times 10^{16}$ & $7.3 \times 10^{15}$ & $1.5 \times 10^{16}$ & $6.9 \times 10^{15}$ & - \\
\hline & $\mu_{\mathrm{p}}\left[\mathrm{cm}^{2} \mathrm{~V}^{-1} \mathrm{~s}^{-1}\right]$ & 0.82 & 13.8 & 2.4 & 15.3 & - \\
\hline
\end{tabular}

Table 1. Properties of $\mathrm{SnS}$ films deposited at two different temperatures and thicknesses, compared to JCPDS card \#039-0354; (a) Bragg angle $\theta$ and calculated grain size $\tau$ for each $\{h k l\}$ plane; (b) the ratio of intensities of (111), (101), and (002) peaks normalized by (040) peak; (c) optical energy gap; (d) lateral resistivity $\rho$, hole density, and hole mobility $\mu_{\mathrm{p}}$. 
Table of contents: Pure, stoichiometric, single-phase tin monosulfide (SnS) thin films are successfully deposited by atomic layer deposition (ALD) using the reaction of bis $\left(N, N^{\prime}\right.$ diisopropylacetamidinato)tin(II) $\left[\mathrm{Sn}\left(\mathrm{MeC}\left(\mathrm{N}^{i}{ }^{i} \mathrm{Pr}\right)_{2}\right)_{2}\right]$ and hydrogen sulfide $\left(\mathrm{H}_{2} \mathrm{~S}\right)$ at low temperatures $\left(100\right.$ to $200{ }^{\circ} \mathrm{C}$ ). This material is a promising absorber layer in thin film solar cells since it is cheap, non-toxic, and earth-abundant, potentially providing inexpensive PV modules to reach the global energy demand at TW levels.

Keyword: Thin Films; Electro-Optical Materials; Structure-Property Relationships

Title: Atomic Layer Deposition of Tin Monosulfide Thin Films

P. Sinsermsuksakul, J. Heo, W. Noh, A. S. Hock, and R. G. Gordon *

\section{ToC figure:}

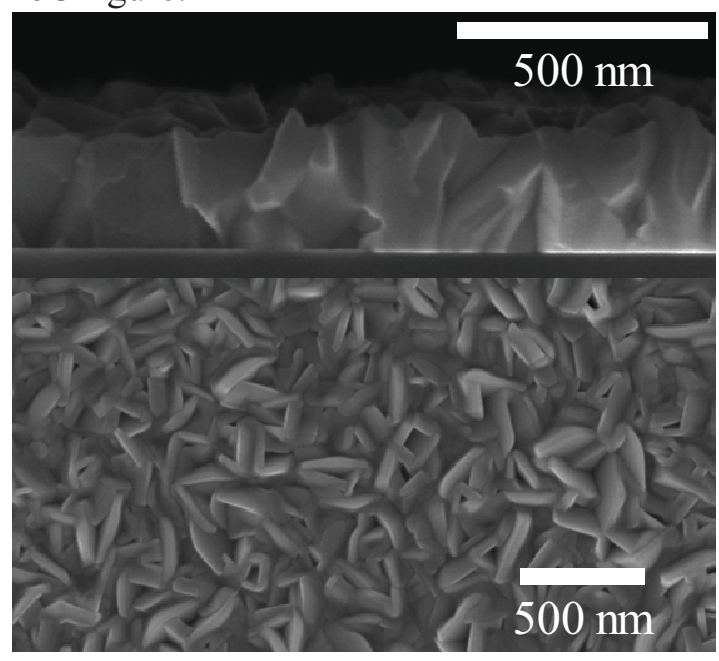

